УДК 631.816.1:633.31/37

DOI https://doi.org/10.32848/agrar.innov.2021.8.3

\title{
ДИНАМІКА ФОРМУВАННЯ ЛИСТКОВОЇ ПОВЕРХНІ ЧИНИ ПОСІВНОЇ ТА ПРОДУКТИВНІСТЬ ІІЇ ФОТОСИНТЕТИЧНОЇ ДІЯЛЬНОСТІ ЗАЛЕЖНО ВІД РІВНЯ МІНЕРАЛЬНОГО ЖИВЛЕННЯ
}

\author{
ГАНГУР В.В. - доктор сільськогосподарських наук \\ https://orcid.org/ 0000-0002-5619-492Х \\ Полтавський державний аграрний університет \\ ЄРЕМКО Л.С. - кандидат сільськогосподарських наук \\ https://orcid.org/ 0000-0001-5641-7436 \\ Полтавський державний аграрний університет \\ САЄНкО В.О. - здобувач ступеня вищої освіти Доктор фрілософії \\ https://orcid.org//0000-0001-9321-817X \\ Полтавський державний аграрний університет
}

Постановка проблеми. Вагомим аспектом подолання проблеми продовольчої та екологічної безпеки України $€$ збільшення виробництва продукції зернобобових культур, здатних фрормувати стабільні врожаї за різних агроекологічних умов. У цьому відношенні значну увагу привертає до себе чина посівна (Lathirus sativus L.), яка характеризується високою поживною цінністю і використовується на продовольчі, кормові, технічні цілі [1; 2]. За рахунок антиоксидантної, антидіабетичної, знеболюючої, жарознижуючої і кардіозахисної властивостей ця культура має широке використання у фрармакологічній промисловості [3].

Чина посівна, рослини якої характеризуються морозостійкістю на початкових етапах розвитку, високою жаро- та посухостійкістю, стійкістю до підтоплення і засолення грунту й ураження хворобами і шкідниками, $€$ досить привабливою культурою для вирощування в регіонах з екстремальними екологічними умовами, де інші зернобобові культури не забезпечують належної продуктивності [4]. Після збирання врожаю цієї культури у грунт надходить близько 67 кг/га азоту як за рахунок здатності до фріксації молекулярного азоту повітря, так і з пожнивними та кореневими рештками [5].

Головним стримуючим фрактором споживання чини посівної $€$ наявність у її рослинах антипоживних речовин, які мають нейротоксичну дію і за постійного споживання можуть викликати незворотній параліч [6; 7]. Негативний ефрект антипоживних речовин може бути зведений до мінімуму шляхом застосування відповідних методів оброблення, що покращує харчовий склад і зовнішню привабливість зерна [8]. Удосконалення сортів чини посівної на генетичному рівні дало змогу знизити рівень умісту в зерні $\beta$-ODAP від 0,5-2,5 \% до менш ніж $0,10 \%$ [9].

Аналіз останніх досліджень і публікацій. Основою первинної продуктивності рослин $€$ сукупність окремих взаємопов'язаних фрізіолого-біохімічних процесів. Серед останніх основна роль належить фотосинтезу, під час якого відбувається перетворення сонячної енергії в енергію хімічних зв'язків і створення матеріальної та енергетичної основи для росту й розвитку рослин [10]. Фотосинтез як основний процес метаболізму в рослині забезпечує енергосубстратне форування врожаю, поєднане із процесами поглинання елементів мінерального живлення протягом вегетаційного періоду. Разом із тим засвоєння поживних речовин визначає інтенсивність перебігу всіх фрізіолого-біохімічних процесів у рослинному організмі та залежить від них [11]. Провідну роль під час поглинання енергії фотосинтетично активної радіації, яка надходить до рослин, відіграють листкові пластинки. Тому важливою умовою підвищення рівня продуктивності рослин $€$ забезпечення формування асиміляційного апарату оптимальних розмірів та підтримання його функціонування протягом максимально тривалого періоду.

Основним чинником забезпечення ростових процесів рослин $є$ забезпеченість їх необхідними у певний період розвитку елементами мінерального живлення, серед яких найважливішим є азот [12; 13]. Його нестача у грунті призводить до порушення процесів формування хлоропластів листя і зниження активності фотосинтетичного апарату, пригнічення ростових процесів. Однак надлишок азоту може призвести до подовження тривалості періоду вегетації, наростання значної вегетативної маси та вилягання рослин, посилення їх вразливості до низки хвороб і шкідників.

Чина посівна, як і інші зернобобові культури, здатна фріксувати молекулярний азот повітря внаслідок симбіотичної взаємодії із бульбочковими бактеріями, забезпечуючи свою потребу у цьому елементі живлення на $22-78 \%$ [14]. Проте для забезпечення рослин усіма необхідними елементами мінерального живлення і досягнення високої їх продуктивності деякі науковці рекомендують вносити у грунт мінеральний азот, оскільки протягом вегетаційного періоду можуть скластися досить несприятливі умови функціонування бобово-ризобіального симбіозу [15].

Фосфрор міститься у складі АТФ, що є джерелом енергії, яка під час процесів фотосинтезу та окислювального фосфорилювання використовується для росту й розвитку рослин, поглинання поживних речовин із ґрунту, синтезу органічних сполук і їх транспортування [16]. Калій активує понад 60 ферментних систем, які здійснюють метаболічні реакції у рослинному організмі. За рахунок рухомості та здатності переносити фотоасиміляти від листкових пластинок до інших органів рослини калій надає стимулюючу дію перебігу фотосинтезу. Цей елемент відіграє вагому роль у регулюванні 
водного режиму рослин, що пояснюється підтриманням його іонів відповідного стану колоїдів цитоплазми [15].

Функціонування всіх життєво важливих систем рослинного організму забезпечується за рахунок наявності мікроелементів, які $€$ складовою частиною фрізіологічно активних речовин і за участю яких здійснюються процеси синтезу й обміну органічних сполук, поглинання та вивільнення енергії [17].

Рекомендованими агротехнологічними прийомами оптимізації мінерального живлення рослин як основного фактору підвищення фотосинтетичної продуктивності $€$ внесення мінеральних добрив і проведення позакореневого підживлення мікродобривами. Важливого значення водночас набуває визначення оптимального співвідношення елементів мінерального живлення з урахування наявності їх у грунті та потреби в них.

Мета дослідження - з'ясування впливу різних норм мінеральних добрив, допосівної обробки насіння мікробіологічним препаратом на основі азотфріксуючих мікроорганізмів та підживлення посівів мікродобривом на динаміку формування листкової поверхні чини, тривалість і продуктивність ії фротосинтетичної роботи.

Матеріали та методика досліджень. Поставлене завдання було виконано під час проведення польових досліджень в умовах дослідного поля ДП «ДГ «Степне» Інституту свинарства і АПВ НААН Полтавського району Полтавської області протягом 2018-2020 pp.

Грунтовий покрив дослідних ділянок представлений чорноземом типовим важкосуглинковим. Уміст гумусу в шарі грунту 0-20 см становить 4,5 \%, азоту, що гідролізується $(5,44-8,10$ мг) (за Тюріним і Кононовою), рухомого фосффору - 10,0-15,0 мг (за Чириковим), калію 16-20 мг на 100 г ґрунту (за Масловою). Грунтовий розчин має слабкокислу реакцію, рН сольової витяжки знаходиться на рівні 6,1. Гідролітична кислотність становить 2,1-2,3 мг-екв. на 100 г ґрунту.

Погодні умови вегетаційного періоду за роки дослідження були неоднорідними, що дозволило всебічно оцінити вплив агротехнологічних прийомів, які вивчали, на формування асиміляційного апарату рослин чини посівної, тривалість і продуктивність їх фотосинтетичної роботи.

Схема досліду передбачала внесення мінеральних добрив у дозах $\mathrm{N}_{20} \mathrm{P}_{40} \mathrm{~K}_{40}, \mathrm{~N}_{40} \mathrm{P}_{40} \mathrm{~K}_{40}$, допосівну інокуля- цію насіння комплексом мікробіологічного препарату Різолайн $(3,0$ л/т) і біопротектора Різосейв $(1,0$ л/т), іï поєднання 3 позакореневим підживленням рослин у фазі гілкування мікродобривом Авангард Р Бобові (2 л/га), а також комплексне застосування інокулянту і біопротектора з макро- і мікродобривами.

Варіанти досліджень розміщували послідовно. Повторність - чотириразова. Посівна площа ділянки $80 \mathrm{~m}^{2}$, облікова - $40 \mathrm{~m}^{2}$. Технологія вирощування чини посівної $є$ загальноприйнятою для зони Лівобережного Лісостепу за виключенням прийомів, що вивчали.

Величину площі листкової поверхні визначали в динаміці у відповідні фрази росту й розвитку методом «висічок», а фотосинтетичний потенціал посіву і чисту продуктивність фотосинтезу - за методикою А. А. Ничипоровича [18]. Масу абсолютно сухої речовини рослин визначали шляхом висушування до постійної маси за температури $105 \mathrm{C}^{\circ}$ паралельних наважок, взятих із проб двох несуміжних повторень [19]. Облік урожаю зерна 3 ділянок здійснювали за допомогою селекційного комбайна «Sampo-500».

Результати досліджень. Експериментальні результати польового досліду свідчать про нерівномірність перебігу формування асиміляційної поверхні чини посівної упродовж вегетаційного періоду. На початкових етапах розвитку рослин, від появи сходів до настання гілкування, їхня листкова поверхня збільшувалася досить повільно, що пояснюється інтенсивним формуванням кореневої системи (табл. 1).

Від фази початку бутонізації темпи наростання фотосинтетичного апарату збільшувались і досягали максимуму у період від цвітіння до формування бобів. До початку наливу бобів величина листкової поверхні посівів досягала розмірів 32,7-38,2 тис. м²/га. Надалі внаслідок відмирання листків нижніх ярусів, починаючи від фази дозрівання бобів, значення цього показника зменшилися на 12,2-17,0 \%.

Суттєвий вплив на формування асиміляційного апарату рослин мало мінеральне удобрення, проведення допосівної обробки насіння комплексом мікробіологічного препарату Різолайн (3,0 л/т), біопротектора Різосейв $(1,0$ л/т) та їх поєднання з позакореневим підживленням рослин у фразі гілкування мікродобривом

Таблиця 1

Динаміка формування асиміляційної поверхні посівів чини залежно від рівнів живлення, тис. $\mathrm{M}^{2} /$ га (середнє за 2018-2020 рр.)

\begin{tabular}{|l|c|c|c|c|c|}
\hline \multicolumn{1}{|c|}{ Варіант досліду } & \multicolumn{5}{c|}{ Фази росту і розвитку рослин } \\
\cline { 2 - 6 } & гілкування & цвітіння & $\begin{array}{c}\text { формування } \\
\text { бобів }\end{array}$ & $\begin{array}{c}\text { налив } \\
\text { бобів }\end{array}$ & $\begin{array}{c}\text { побуріння } \\
\text { бобів }\end{array}$ \\
\hline Контроль & 16,2 & 25,8 & 32,7 & 35,8 & 29,7 \\
\hline $\mathrm{N}_{20} \mathrm{P}_{40} \mathrm{~K}_{40}$ & 18,3 & 30,7 & 35,2 & 37,1 & 32,6 \\
\hline $\mathrm{N}_{40} \mathrm{P}_{40} \mathrm{~K}_{40}$ & 19,1 & 34,4 & 36,7 & 38,4 & 33,4 \\
\hline Різолайн + Різосейв & 16,8 & 26,8 & 34,5 & 36,3 & 30,4 \\
\hline Різолайн + Різосейв + Авангард Р Бобові & 17,4 & 28,2 & 34,9 & 36,7 & 30,9 \\
\hline $\begin{array}{l}\mathrm{N}_{40} \mathrm{P}_{40} \mathrm{~K}_{40}+\text { Різолайн + Різосейв + } \\
\text { Авангард Р Бобові }\end{array}$ & 19,5 & 32,3 & 37,7 & 39,9 & 34,2 \\
\hline $\begin{array}{l}\mathrm{N}_{40} \mathrm{P}_{40} \mathrm{~K}_{40}+\text { Різолайн + Різосейв + } \\
\text { Авангард Р Бобові }\end{array}$ & 20,4 & 33,8 & 38,2 & 41,3 & 35,1 \\
\hline
\end{tabular}


Авангард Р Бобові (2 л/га). У період найінтенсивнішого наростання листкової поверхні ії̈ максимальні розміри (41,3 тис. м²/га) забезпечило поєднання вищезазначених елементів технології вирощування.

Слід відмітити важливе значення азотних добрив у формуванні листкової поверхні посівів. У варіанті із внесенням половинної дози азоту площа листкової поверхні посівів зменшувалася на 3,4 \% порівняно з повним азотним удобренням. Внесення мінеральних добрив, проведення інокуляції насіння та ії̈ поєднання з позакореневим підживленням рослин в якості окремих агротехнічних прийомів виявилося менш ефективним для оптимізації умов формування асиміляційного апарату рослин, на що вказує зменшення площі листкової поверхні відповідно до 37,1-38,4, 36,3 та 36,7 тис. м²/га порівняно з варіантом їх сумісного застосування.

Однією з умов найповнішої реалізації генетично обумовленого потенціалу продуктивності є тривале функціонування асиміляційної поверхні оптимальних розмірів. Сумарна характеристика фоотосинтетичної діяльності рослин протягом вегетаційного періоду виражається фотосинтетичним потенціалом, величина якого змінювалася залежно від умов вирощування чини. У варіантах внесення мінеральних добрив значення фотосинтетичного потенціалу збільшилися на 8,72-12,3 \% відносно контролю, причому більшим воно було за внесення повної дози азоту. Внаслідок допосівного оброблення насіння комплексом мікробіологічного препарату на основі азотфіксуючих мікроорганізмів та біопротектору, а також за поєднання цих елементів із позакореневим підживленням рослин мікродобривом значення цього показника становили на рівні 1212 і 1239 млн. м²/га за добу. Найкращі умови для функціонування асиміляційного апарату рослин створювалися за поєднання допосівної обробки насіння і позакореневого підживлення рослин на фоні внесення $\mathrm{N}_{40} \mathrm{P}_{40} \mathrm{~K}_{40}$, у цьому варіанті досліду фотосинтетичний потенціал посівів збільшувався порівняно з контролем на 16,9% (табл. 2).

Активність функціонування одиниці листкової поверхні під час створення органічної біомаси протягом вегетаційного періоду характеризує показник чистої продуктивності фоотосинтезу [20]. Посіви із тривалим функціонуванням добре розвиненого фотосинтетичного апарату були більш продуктивними.

Кількість органічної речовини, синтезованої за добу одиницею листкової поверхні, в середньому за період вегетації була найвищою $(5,12$ г м²) у варіанті поєднання прийомів внесення мінеральних добрив дозою $\mathrm{N}_{40} \mathrm{P}_{40} \mathrm{~K}_{40}$, інокуляції насіння та позакореневого підживлення рослин. Внесення мінеральних добрив сприяло підвищенню показника чистої продуктивності фото-

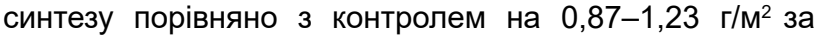
добу. У варіантах із проведенням допосівної інокуляції насіння та поєднанням її із позакореневим підживленням рослин кількість синтезованої органічної речовини

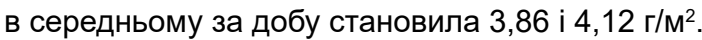

Разом із підвищенням показників продуктивності фотосинтетичної роботи збільшувалися показники накопиченої рослинами абсолютно сухої біомаси. Загалом у досліді спостерігався стимулюючий ефект макроі мікроелементів та інтродукованих штамів азотфіксуючих мікроорганізмів на накопичення рослинами органічної біомаси. Найінтенсивніше цей процес відбувався за поєднання всіх елементів технології, що вивчали, про що свідчить збільшення маси абсолютно сухої речовини рослин до 658 г з $1 \mathrm{~m}^{2}$. У варіантах застосування мікробіологічного препарату і біопротектору для допосівної обробки насіння та їх сумісного використання з мікродобривом маса сухої речовини рослин у фразу гілкування становила 495 і 528 г/м² відповідно. На фонах мінерального удобрення інтенсивність накопичення продуктів асиміляції чиною посівною була вищою: на $1 \mathrm{~m}^{2}$ площі накопичувалося 586-623 г сухої біомаси рослин.

Після цвітіння, запилення і запліднення боби і насіння ставали потужними атрагуючими центрами мобілізації і споживання фотоасимілятів. Відповідно спрямованість і швидкість їх пересування в рослинному організмі визначали величину основних структурних елементів продуктивності рослин та загальну урожайність посівів (табл. 3). Найкращі умови для цього створювалися за комплексного застосування макро- і мікроелементів та допосівної обробки насіння мікробіологічним препаратом на основі азотфріксуючих мікроорганізмів, унаслідок чого зернова продуктивність посівів зросла порів-

Таблиця 2

Вплив забезпеченості посівів чини посівної елементами мінерального живлення на величину фітометричних показників рослин, (середнє за 2018-2020 рр.)

\begin{tabular}{|c|c|c|c|}
\hline Варіант досліду & $\begin{array}{c}\text { Фотосинтетичний } \\
\text { потенціал, } \\
\text { млн. м²/га діб } \\
\end{array}$ & $\begin{array}{c}\text { Чиста продуктивність } \\
\text { фотосинтезу, г/м² } \\
\text { за добу }\end{array}$ & $\begin{array}{c}\text { Маса рослини } \\
\text { в абсолютно } \\
\text { сухому стані, } r / \mathrm{M}^{2} \\
\end{array}$ \\
\hline Контроль & 1172 & 3,38 & 452 \\
\hline $\mathrm{N}_{20} \mathrm{P}_{40} \mathrm{~K}_{40}$ & 1284 & 4,25 & 586 \\
\hline $\mathrm{N}_{40} \mathrm{P}_{40} \mathrm{~K}_{40}$ & 1337 & 4,61 & 623 \\
\hline Різолайн + Різосейв & 1212 & 3,86 & 495 \\
\hline $\begin{array}{l}\text { Різолайн + Різосейв + Авангард Р } \\
\text { Бобові }\end{array}$ & 1239 & 4,12 & 528 \\
\hline $\begin{array}{l}\mathrm{N}_{20} \mathrm{P}_{40} \mathrm{~K}_{40}+\text { Різолайн + Різосейв + } \\
\text { Авангард Р Бобові }\end{array}$ & 1367 & 4,78 & 634 \\
\hline $\begin{array}{l}\mathrm{N}_{40} \mathrm{P}_{40} \mathrm{~K}_{40}+\text { Різолайн + Різосейв + } \\
\text { Авангард Р Бобові }\end{array}$ & 1410 & 5,12 & 658 \\
\hline
\end{tabular}


Урожайність зерна чини посівної залежно від забезпеченості рослин елементами мінерального живлення (середнє за 2018-2020 рр.)

\begin{tabular}{|c|c|c|c|c|}
\hline \multirow{2}{*}{ Варіант досліду } & \multicolumn{3}{|c|}{ Урожайність за роками, т/га } & \multirow{2}{*}{ Середнє } \\
\hline & 2018 & 2019 & 2020 & \\
\hline Контроль & 2,44 & 2,08 & 2,18 & 2,23 \\
\hline $\mathrm{N}_{20} \mathrm{P}_{40} \mathrm{~K}_{40}$ & 3,21 & 2,56 & 2,63 & 2,80 \\
\hline $\mathrm{N}_{40} \mathrm{P}_{40} \mathrm{~K}_{40}$ & 3,34 & 2,74 & 2,81 & 2,93 \\
\hline Різолайн + Різосейв & 2,56 & 2,32 & 2,43 & 2,44 \\
\hline Різолайн + Різосейв + Авангард Р Бобові & 2,75 & 2,41 & 2,54 & 2,57 \\
\hline $\mathrm{N}_{20} \mathrm{P}_{40} \mathrm{~K}_{40}+$ Різолайн + Різосейв + Авангард Р Бобові & 3,27 & 2,63 & 2,68 & 2,86 \\
\hline $\mathrm{N}_{40} \mathrm{P}_{40} \mathrm{~K}_{40}+$ Різолайн + Різосейв + Авангард Р Бобові & 3,34 & 2,89 & 2,97 & 3,07 \\
\hline $\mathrm{HIP}_{0,95}$ & 0,12 & 0,15 & 0,14 & - \\
\hline
\end{tabular}

няно з контролем на 27,4 \%. За поєднання цих елементів технології вирощування на фоні внесення половинної дози азоту відзначено відповідне зниження її показника. Внесення мінеральних добрив забезпечило підвищення рівня врожайності зерна чини посівної на 0,57 і 0,70 т/га порівняно з контролем.

Проведення допосівної інокуляції насіння та ії̈ поєднання з позакореневим підживленням дало змогу збільшити зернову продуктивність чини до 2,44 та 2,57 т/га відповідно.

Висновки. Отже, інтенсивність формування асиміляційної поверхні посівів змінювалася протягом вегетаційного періоду рослин чини посівної. Найвищим цей показник був у період формування-початку наливу бобів і насіння. Розміри фотосинтезуючого апарату рослин, тривалість і продуктивність його активного функціонування зумовлені покращенням поживного режиму рослин за рахунок інтродукції у ризосферу мікробіологічного препарату на основі азотфріксуючих мікроорганізмів та їх забезпечення доступними формами елементів мінерального живлення.

Найдоцільнішим виявилося поєднання допосівної інокуляції насіння з позакореневим підживленням рослин на фоні внесення $\mathrm{N}_{40} \mathrm{P}_{40} \mathrm{~K}_{40}$, за якого внаслідок подовження періоду продуктивної фотосинтетичної діяльності добре розвиненої асиміляційної поверхні відбулося підвищення зернової продуктивності посівів до 3,07 т/га.

\section{СПИСОК ВИКОРИСТАНОÏ ЛІТЕРАТУРИ:}

1. Вишнякова М. А., Бурляева М. О. Потенциал хозяйственной ценности и перспективы использования российских видов чины. Сельскохозяйственная биология. 2006. № 6. С. 85-97.

2. Силенко С. І., Єремко Л. С., Силенко О. С., Роговий О. Ю., Андрущенко О. В., Гангур В. В. Добір вихідного матеріалу чини посівної (Lathirus sativus L.) для створення посухостійких сортів. Вісник ПДАА. 2020. № 3. C. 99-108. URL: https://doi.org/10.31210/ visnyk2020.03.1.

3. Al-SnafiA.E. ChemicalConstituentsandPharmacological Effects of Lathyrus Sativus - A Review. IOSR Journal of Pharmacy (IOSRPHR). 2019. Vol. 9. P. 51-58.

4. Hailu D., Abera S., Teka T. A. Effects of processing on nutritional composition and anti-nutritional factors of grass pea (Lathyrus Sativus L): A Review. Food Science and Quality Management. 2015. Vol. 36. P. 61-71.
5. Lambein F., Travella S., Kuo Y. H., Montagu M. V., Marc Heijde. Grass pea (Lathyrus sativus L.): orphan crop, nutraceutical or just plain food? Planta. 2019. Vol. 250. P. 821-838. URL: https://doi.org/ 10.1007/s00425-018-03084-0.

6. Kumar S., Bejiga G., Ahmed S., Nakkoul H., Sarker A. Genetic improvement of grass pea for low neurotoxin ( $\beta$-ODAP) content. Food and Chemical Toxicology. 2011. Vol. 49. P. 589-600. URL: https:// doi.org/10.1016 / j.fct.2010.06.051.

7. Mehmet A. Fatty acid characteristics of grass pea (Lathyrus sativus) in an East Mediterranean environment. Cogent Chemistry. 2017. Vol. 3. P. 1-9. URL: https://doi.org/10.1080/23312009.2017.1296748.

8. Khandare A. L., Kumar R. H., Meshram I. I., Arlappa N., Laxmaiah A., Venkaiah K., Rao P. A., Validandi V., Toteja G. S. Current scenario of consumption of Lathyrus sativus and lathyrism in three districts of Chhattisgarh State, India. Toxicon. 2018. Vol. 150. P. 228-234. URL: https://doi.org/10.1016 / j.toxicon.2018.06.069.

9. Rybiński W., Karamać M., Sulewska K., Börner A., Amarowicz R. Antioxidant potential of grass pea seeds from European countries. Foods. 2018. Vol. 7. P. 142-153. URL: https://doi.org/10.3390/foods7090142.

10. Ничипорович А. А. О путях повышения продуктивности фотосинтеза растений в посевах. Фотосинтез и вопросы продуктивности растений. Москва : Изд-во АН СССР, 1963. С. 5-36.

11. Tokarz K. M., Wesołowski W., Tokarz B., Makowski W., Wysocka A., Jedrzejczyk R. J., Chrabaszcz K., Malek K., Kostecka-Gugała A. Stem photosynthesis - a key element of grass pea (Lathyrus sativus L.) acclimatisation to salinity. International Journal of Molecular Sciences. 2021. Vol. 22. P. 685-718. URL: https://doi.org/10.3390/ ijms22020685.

12. Єремко Л. С., Швець А. Ю., Кобилинський І. В., Саєнко В. О. Оптимізація поживного режиму - фрактор підвищення продуктивності посівів чини посівної (Lathirus sativus L.). Вісник ПДАА. 2021. № 1. C. 149-155. URL: https://doi.org/10.31210/visnyk2021. 01.18 .

13. Єремко Л. С., Гангур В. В., Киричок О. О., Сокирко Д. П. Мінеральне живлення як фрактор підвищення фотосинтетичної продуктивності і урожайності посівів гороху. Вісник ПДАА. 2019. № 3. С. 50-56. URL: https://doi.org/10.31210/visnyk2019.03.06.

14. Сокирко Д. П., Гангур В. В., Єремко Л. С. Вплив елементів технології вирощування на формування 
симбіотичного апарату зернобобових культур. Colloquium-journal. 2021. № 10 (97). P. 30-32.

15. Li X., Zen R., Liao H. Improving crop nutrient efficiency through root architecture modification. Journal of Integrative Plant Biology. 2016. Vol. 58. P. 193-202. URL: https://doi.org/10.1111/jipb.12434.

16. Mart'inez-Ballesta M. C., Dominguez-Perles R., Moreno D. A., Muries B., Alcaraz-Lopez C., Bast'ias E., Garc'ia-Viguera C., Carvaja M. Minerals in plant food: effect of agricultural practices and role in human health. A review. Agronomy for Sustainable Development. 2010. Vol. 30. P. 295-309.

17. Попов В. В. Содержание микроэлементов в почвах юго-востока Ростовской области. Агрохимический вестник. 2002. № 3. С. 37-38.

18. Ничипорович А. А., Строганова Л. Э., Чмора С. Н., Власова М. П. Фотосинтетическая деятельность растений в посевах. Москва : Издательство АН СССР, 1961. 133 C.

19. Ничипорович А. А. Фотосинтетическая деятельность растений и пути повышения их продуктивности. Теоретические основы фотосинтетической продуктивности. Москва : Наука, 1972. 527 с.

20. Кошкин Е. И. Частная физиология полевых культур. Учеб. пособ. Москва : Колос, 2005. 344 с.

\section{REFERENCES}

1. Vyshniakova, M. A., Burliaeva, M. O. (2006). Potentsyal khoziaistvennoi tsennosty y perspektyvы yspolzovanyia rossyiskykh vydov chynы [The potential of economic value and the prospects for the use of Russian types of grass pea]. Selskokhoziaistvennaia byolohyia Agricultural biology, 6, 85-97 [in Russian].

2. Sylenko, C. I., Yeremko, L. S., Sylenko, O. S., Rohovyi, O. Yu., Andrushchenko, O. V., Hanhur, V. V. (2020). Dobir vykhidnoho materialu chyny posivnoi (Lathirus sativus L.) dlia stvorennia posukhostiikykh sortiv [Choosing parent material of grass peavine (Lathirus sativus $L$.) for creating drought resistant varieties]. Visnyk PDAA - Bulletin of PSAA, 3, 99-108. URL: https:// doi.org/10.31210/visnyk2020.03.1 [in Ukrainian].

3. Al-Snafi, A. E. (2019). Chemical Constituents and Pharmacological Effects of Lathyrus Sativus A Review. IOSR Journal of Pharmacy (IOSRPHR), 9, 51-58 [in English].

4. Hailu, D., Abera, S., Teka, T. A. (2015). Effects of processing on nutritional composition and anti-nutritional factors of grass pea (Lathyrus Sativus L): A Review. Food Science and Quality Management, 36, 61-71 [in English].

5. Lambein, F., Travella, S., Kuo, Y. H., Montagu, M. V., Marc, H. (2019). Grass pea (Lathyrus sativus L.): orphan crop, nutraceutical or just plain food? Planta, 250, 821-838. URL: https://doi.org/10.1007/ s00425-018-03084-0 [in English].

6. Kumar, S., Bejiga, G., Ahmed, S., Nakkoul, H., Sarker, A. (2011). Genetic improvement of grass pea for low neurotoxin ( $\beta$-ODAP) content. Food and Chemical Toxicology, 49, 589-600. URL: https://doi.org/10.1016/ j.fct.2010.06.051 [in English].

7. Mehmet, A. (2017). Fatty acid characteristics of grass pea (Lathyrus sativus) in an East Mediterranean environment. Cogent Chemistry, 3, 1-9. URL: https://doi.org/ 10.1080/23312009.2017.1296748 [in English].
8. Khandare, A. L., Kumar, R. H., Meshram, I. I., Arlappa, N., Laxmaiah, A., Venkaiah, K., Rao, P. A., Validandi, V., Toteja, G. S. (2018). Current scenario of consumption of Lathyrus sativus and lathyrism in three districts of Chhattisgarh State, India. Toxicon, 150, 228-234. URL: https://doi.org/10.1016/j.toxicon.2018.06.069 [in English].

9. Rybiński, W., Karamać, M., Sulewska, K., Börner, A., Amarowicz, R. (2018). Antioxidant potential of grass pea seeds from European countries. Foods, 7, 142-153. URL: https://doi.org/10.3390/foods7090142 [in English].

10. Nychyporovych, A. A. (1963). O putiakh povbshenyia produktyvnosty fotosynteza rastenyi $\mathrm{v}$ posevakh. Fotosyntez y voprost produktyvnosty rastenyi [About the ways of increasing the productivity of plant photosynthesis in crops. Photosynthesis and questions of plant productivity]. M.: Yzd-vo AN SSSR, 5-36 [in Russian].

11. Tokarz, K. M., Wesołowski, W., Tokarz, B., Makowski, W., Wysocka, A., Jedrzejczyk, R. J., Chrabaszcz, K., Malek, K., Kostecka-Gugała, A. (2021). Stem photosynthesis - a key element of grass pea (Lathyrus sativus L.) acclimatisation to salinity. International Journal of Molecular Sciences, 22, 685-718. URL: https://doi. org/10.3390/ijms22020685 [in English].

12. Yeremko, L. S., Shvets, A. Yu., Kobylynskyi, I. V., Saienko, V. O. (2021). Optymizatsiia pozhyvnoho rezhymu - faktor pidvyshchennia produktyvnosti posiviv chyny posivnoi (Lathirus sativus L.) [Nutritive regime optimization as a factor of increasing crop productivity of grass peavine (Lathirus sativus L.). Visnyk PDAA - Bulletin of PSAA, 1, 149-155. URL: https:// doi.org/10.31210/visnyk2021.01.18 [in Ukrainian].

13. Yeremko, L. S., Hanhur, V. V., Kyrychok, O. O., Sokyrko, D. P. (2019). Mineralne zhyvlennia yak faktor pidvyshchennia fotosyntetychnoi produktyvnosti i urozhainosti posiviv horokhu [Mineral nutrition as a factor of increasing photosynthetic productivity and yield of field pea]. Visnyk PDAA-Bulletin of PSAA, 3, 50-56. URL: https://doi.org/10.31210/visnyk2019.03.06 [in Ukrainian].

14. Sokyrko, D. P., Hanhur, V. V., Yeremko, L. S. (2021). Vplyv elementiv tekhnolohii vyroshchuvannia na formuvannia symbiotychnoho aparatu zernobobovykh kultur [Impact of grooving technology elements on the formation of leguminous crops symbiotic apparatus]. Colloquium-journal, 10 (97), 30-32 [in Poland].

15. Li, X., Zen, R., Liao, H. (2016). Improving crop nutrient efficiency through root architecture modification. Journal of Integrative Plant Biology, 58, 193-202. URL: https://doi.org/10.1111/jipb.12434 [in English].

16. Mart'inez-Ballesta, M. C., Dominguez-Perles, R., Moreno, D. A., Muries, B., Alcaraz-Lopez, C., Bast'ias, E., Garc'ia-Viguera, C., Carvaja, M. (2010). Minerals in plant food: effect of agricultural practices and role in human health. A review. Agronomy for Sustainable Development, 30, 295-309 [in English].

17. Popov, V. V. (2002). Soderzhanye mykroэlementov v pochvakh yuho-vostoka Rostovskoi oblasty [The content of trace elements in the soils of the Southeast of the Rostov region]. Ahrokhymycheskyi vestnyk Agrochemical Bulletin, 3, 37-38 [in Russian].

18. Nychyporovych, A. A., Strohanova, L. Э., Chmora, S. N., Vlasova, M. P. (1961). Fotosyntetycheskaia deiatelnost rastenyi $v$ posevakh [Photosynthetic activity of 
plants in crops]. Moskva: Yzdatelstvo AN SSSR, 133 [in Russian].

19. Nychyporovych, A. A. (1972). Fotosyntetycheskaia deiatelnost rastenyi y puty povыshenyia ykh produktyvnosty. Teoretycheskye osnovы fotosyntetycheskoi produktyvnosty [Photosynthetic activity of plants and ways to increase their productivity. Theoretical foundations of photosynthetic productivity]. Moskva: Nauka, 527 [in Russian].

20. Koshkyn E. Y. (2005) Chastnaia fyzyolohyia polevыkh kultur [Private physiology of field crops]. Ucheb. posob. Moskva: Kolos, 344 [in Russian].

Гангур В.В., Єремко Л.С., Саєнко В.О. Динаміка формування листкової поверхні чини посівної та продуктивність її фотосинтетичної діяльності залежно від рівня мінерального живлення

Мета дослідження - з'ясування впливу різних норм мінеральних добрив, допосівної обробки насіння мікробіологічним препаратом на основі азотфіксуючих мікроорганізмів та підживлення посівів мікродобривами на динаміку формування листкової поверхні чини посівної, тривалість і продуктивність її фотосинтетичної роботи.

Методи. Дослідження проведено в умовах дослідного поля ДП «ДГ «Степне» Інституту свинарства і АПВ НААН Полтавського району Полтавської області протягом 2018-2020 рр. Ми вивчали такі елементи технології вирощування: внесення мінеральних добрив у дозах $\mathrm{N}_{20} \mathrm{P}_{40} \mathrm{~K}_{40}, \mathrm{~N}_{40} \mathrm{P}_{40} \mathrm{~K}_{40}$, проведення допосівної інокуляції насіння комплексом мікробіологічного препарату Різолайн $(3,0$ л/т) і біопротектора Різосейв $(1,0$ л/т), її поєднання 3 позакореневим підживленням рослин у фазі гілкування мікродобривом Авангард Р Бобові (2 л/га), а також комплексне застосування інокулянту й біопротектора з макро- і мікродобривами.

Результати досліджень свідчать про суттєвий позитивний вплив агротехнологічних прийомів, які вивчали, на динаміку формування листкової поверхні рослин і тривалість ії активної фотосинтезуючої роботи. Найсприятливішою умовою функціонування асиміляційного апарату рослин (що визначали за накопиченням рослинами значної кількості органічної надземної біомаси) $є$ поєднання допосівної обробки насіння та позакореневого підживлення рослин на фоні внесення $\mathrm{N}_{40} \mathrm{P}_{40} \mathrm{~K}_{40}$ : у цьому варіанті досліду зернова продуктивність посівів була найвищою і становила 3,07 т/га.

Урожайність зерна на фонах мінерального удобрення $\mathrm{N}_{20} \mathrm{P}_{40} \mathrm{~K}_{40}$ і $\mathrm{N}_{40} \mathrm{P}_{40} \mathrm{~K}_{40}$ становила 2,80 і 2,93 т/га відповідно, що вище контролю на 20,3 і 23,9 \%. Проведення допосівної інокуляції насіння та ії̈ поєднання з позакореневим підживленням рослин дало змогу збільшити зернову продуктивність посівів чини до 2,44 та 2,57 т/га відповідно.

Висновки. Розміри фотосинтезуючого апарату рослин, тривалість і продуктивність його активного функціонування зумовлені покращенням поживного режиму рослин за рахунок інтродукції у ризоссреру мікробіологічного препарату на основі азотфріксуючих мікроорганізмів та їх забезпечення доступними формами елементів мінерального живлення.

Найдоцільнішим виявилося поєднання допосівної інокуляції насіння з позакореневим підживленням рослин на фоні внесення $\mathrm{N}_{40} \mathrm{P}_{40} \mathrm{~K}_{40}$, унаслідок чого за рахунок подовження періоду продуктивної фотосинтетичної діяльності добре розвиненої асиміляційної поверхні відбулося збільшення зернової продуктивності посівів за умов недостатнього зволоження до 3,07 т/га.
Ключові слова: чина посівна (Lathirus sativus L.), площа листкової поверхні, фотосинтетичний потенціал, чиста продуктивність фотосинтезу, інокуляція, мінеральні добрива, мікродобрива, урожайність зерна.

Hanhur V.V., Yeremko L.S., Saienko V.O. Dynamics of leaf surface formation of grass pea and productivity of its photosynthetic activity depending on the level of mineral nutrition.

Purpose - to find out the effect of different mineral fertilizers doses, pre-sowing seed treatment with microbiological preparation on the basis of nitrogen-fixing microorganisms and foliar fertilization with micronutrients on the dynamics of leaf surface formation, sowing duration and photosynthetic productivity.

Methods. The researches were conducted at the experimental field of the State Research Enterprise «EF "Stepne» of the Institute of Pig Breeding and AIP NAAS» of Poltava district of Poltava region during 2018-2020 years.

The following elements of cultivation technology were studied: application of mineral fertilizers in doses $\mathrm{N}_{20} \mathrm{P}_{40} \mathrm{~K}_{40}, \quad \mathrm{~N}_{40} \mathrm{P}_{40} \mathrm{~K}_{40}$, pre-sowing seed inoculation with a complex of microbiological preparation Rhizoline $(3,0 \mathrm{l} / \mathrm{t})$ and bioprotector Rhizosave $(1,0 \mathrm{l} / \mathrm{t})$, its combination with foliar fertilization in phase of branching with microfertilizer Avangard R Bobovi (2,0 l/ha) and complex application of inoculant and bioprotector with macro- and microfertilizers.

Research results indicate a significant positive effect of studied agro-technological techniques on the plant leaf surface formation dynamics and its active photosynthetic work duration.

The most favorable conditions for the assimilation apparatus functioning, which was expressed in the accumulation of plants a significant amount of organic aboveground biomass were created by a combination of presowing seed treatment, foliar fertilization and mineral fertilizer application at the dose $\mathrm{N}_{20} \mathrm{P}_{40} \mathrm{~K}_{40}$. Accordingly, in this variant, the grain productivity of crops was the highest $-3,07 \mathrm{t} / \mathrm{ha}$.

The grain yields in the variants with mineral fertilizer application at the doses $\mathrm{N}_{20} \mathrm{P}_{40} \mathrm{~K}_{40}$ and $\mathrm{N}_{40} \mathrm{P}_{40} \mathrm{~K}_{40}$ were 2,80 and $2,93 \mathrm{t} / \mathrm{ha}$, respectively, which exceeded the control by 20,3 and $23,9 \%$. Carrying out pre-sowing seed inoculation and its combination with foliar application of plants made it possible to increase the grain productivity of crops to 2,44 and $2,57 \mathrm{t} /$ ha, respectively.

Conclusion. The size of plant photosynthetic apparatus, duration and productivity of its active functioning were due to the improvement of plant nutrition due to the introduction into the rhizosphere of a microbiological preparation based on nitrogen-fixing microorganisms and their provision with available forms of mineral nutrients.

The combination of pre-sowing seed inoculation, foliar fertilization of plants and application of mineral fertilizers in a dose $\mathrm{N}_{40} \mathrm{P}_{40} \mathrm{~K}_{40}$, was most expedient, where due to prolongation of the period of productive photosynthetic activity of well-developed assimilation surface in conditions of insufficient moisture the grain productivity increased to $3.07 \mathrm{t} / \mathrm{ha}$.

Key words: grass pea (Lathirus sativus L.), leaf surface area, photosynthetic potential, net photosynthesis productivity, inoculation, mineral fertilizers, microfertilizers, grain yield. 